\title{
Pr and Gd co-doped bismuth ferrite thin films with enhanced multiferroic properties
}

\author{
CHANG CHUN CHEN*, ZI XUAN LIU, GUI WANG and YI LIN YAN \\ College of Materials Science and Engineering, Nanjing University of Technology, \\ No. 5 Xinmofan Road, Nanjing 210009, China
}

MS received 21 October 2013; revised 25 January 2014

\begin{abstract}
Pr and Gd co-modified $\mathrm{Bi}_{0.95-x} \operatorname{Pr}_{x} \mathrm{Gd}_{0.05} \mathrm{FeO}_{3}(x=0.00,0 \cdot 05,0 \cdot 10)$ (BPGFO) thin films on Pt(111)/ $\mathrm{Ti} / \mathrm{SiO}_{2} / \mathrm{Si}(100)$ substrates were prepared by a sol-gel together with spin coating technique. A detailed study of electrical and magnetic properties of these thin films is reported. X-ray diffraction analysis shows that, with an increase in Pr content, the crystal structures of BPGFO thin films retain rhombohedral (R3c) symmetry accompanied by structure distortion. Polarization-electric field hysteresis loops of these thin films demonstrate that the incorporation of $\mathrm{Pr}$ and $\mathrm{Gd}$ into the $\mathrm{Bi}$ site of $\mathrm{BiFeO}_{3}$ thin film could enhance the ferroelectric performance. Compared to other thin films, the optimal ferroelectric behaviours in $\mathrm{Bi}_{0.85} \operatorname{Pr}_{0.1} \mathbf{G d}_{0.05} \mathrm{FeO}_{3}$ thin film are ascribed to its large dielectric constant, low dissipation factor and low leakage current density. Room temperature magnetization-magnetic field curves of these thin films indicate that all the samples are of paramagnetic behaviours and the enhanced saturation magnetic properties can be found.
\end{abstract}

Keywords. Pr and Gd co-modified $\mathrm{BiFeO}_{3}$ thin film; ferroelectric properties; sol-gel.

\section{Introduction}

In recent years, great attention has been paid to singlephase $\mathrm{BiFeO}_{3}$ (BFO) multiferroic materials crystallized in the $\mathrm{ABO}_{3}$-type perovskite structure with the $\mathrm{R} 3 \mathrm{c}$ space group at room temperature, which display the co-existence of spontaneous electric and magnetic ordering in the same phase (Hill 2000; Fiebig et al 2002). The characteristics of BFO multiferroic materials with attractive functionalities caused by the interaction between electric polarization and magnetization promise some potential applications in advanced magnetoelectric devices (Eerenstein et al 2006). However, as promising as BFO multiferroic materials are, some drawbacks need to be overcome prior to real commercial applications. One problem is that the high leakage current in $\mathrm{BFO}$ materials, mainly originating from various impurity phases $\left(\mathrm{Bi}_{2} \mathrm{Fe}_{4} \mathrm{O}_{9}, \mathrm{Bi}_{36} \mathrm{Fe}_{24} \mathrm{O}_{57}\right.$ and $\left.\mathrm{Bi}_{25} \mathrm{FeO}_{40}\right)$ as well as oxygen vacancies, results in poor ferroelectric behaviour and reliability of magnetoelectric devices (Munoz et al 1985; Qi et al 2005; Kumar and Yadav 2006). The other question is that, even though BFO is a G-type-antiferromagnetic (AFM) ordering, a weak FM component is observed owing to canting of $\mathrm{Fe}^{3+}$ spins at room temperature (Smolenskii and Chupis 1982; Hur et al 2004). As a result, it is necessary to further improve both ferroelectric and magnetic properties of BFO materials for the researchers. At present, it is wellestablished that an appropriate doping in BFO materials via

\footnotetext{
*Author for correspondence (changchunchen@hotmail.com)
}

partial ionic substitution to $\mathrm{Bi}_{1-x} \mathrm{~A}_{x} \mathrm{FeO}_{3}$ ( $\mathrm{A}$ is a lanthanide ion, rare earth metal) or to $\mathrm{BiFe}_{1-x} \mathrm{M}_{x} \mathrm{O}_{3}$ ( $\mathrm{M}$ is another $3 \mathrm{~d}$ transition metal) is a promising way for upgrading multiferroics properties (Lee et al 2006; Takeshi Kawae et al 2008).

Due to the isovalence of $\mathrm{Gd}^{3+}$ ions with respect to $\mathrm{Bi}^{3+}$ ions together with adjacent ionic radius $\left(\mathrm{Gd}^{3+}: 1 \cdot 11 \AA\right.$, $\left.\mathrm{Bi}^{3+}: 1 \cdot 17 \AA\right)$, Gd ion doping is not expected to suppress the oxygen vacancies in BFO materials. However, the suppression of oxygen vacancies is only a cause for the decrease of the leakage current in BFO materials, the aforementioned impurity phases are also responsible for the reduction of leakage of current in BFO materials (Palkar et al 2004; Zhang et al 2006). Gd ion doping is likely to suppress the impurity phases that normally appear in BFO materials and thus reduce the leakage of current that normally happens due to the suppression of the mobile defects (such as ions of $\mathrm{Fe}^{2+}$, vacancy of $\mathrm{O}$ and $\mathrm{Bi}$ ) (Yuan et al 2006). In addition, it is also checked that the enhanced magnetization resulted from the suppression of spatially modulated spin structure that could be observed in Gd doped BFO materials (Naik and Mahendiran 2009). On the other hand, it is known that partial substitutions of $\mathrm{Pr}^{3+}$ at $A$ site for $\mathrm{Bi}^{3+}$ ions of $\mathrm{BFO}$ materials is also an effective way to enhance the multiferroic properties of BFO materials (Yu et al 2008; Singh et al 2013). There are two reasons why enhanced multiferroic properties of BFO materials were observed: (a) the substitution of $\mathrm{Pr}^{3+}$ for $\mathrm{Bi}^{3+}$ ions will prevent the creation of defects, i.e. volatilization of $\mathrm{Bi}$ atoms owing to the strength of $\mathrm{Pr}-\mathrm{O}$ bond $(753 \pm 17 \mathrm{~kJ} / \mathrm{mol})$ being higher than that of 
Bi-O bond (343 $\pm 17 \mathrm{~kJ} / \mathrm{mol}$ ) (Dean 1999) and (b) Pr ion doping will increase the degree of the distortion $(1.126 \AA$ for $\mathrm{Pr}^{3+}$ in eight coordination, $1 \cdot 17 \AA$ for $\mathrm{Bi}^{3+}$ ) (Yu et al 2008), resulting in a smaller bond angle of $\mathrm{Fe}-\mathrm{O}-\mathrm{Fe}$ and a significant magnetization As a result, it is fascinating to study the effect of co-substitution of Pr and Gd on BFO materials in order to have the combined advantages of $\mathrm{Gd}$ and $\mathrm{Pr}$ ion dopants. In this paper, we report preparations of $\mathrm{Pr}$ and $\mathrm{Gd}$ co-doped $\mathrm{Bi}_{0.95-x} \mathrm{Pr}_{x} \mathrm{Gd}_{0.05} \mathrm{FeO}_{3}(x=0.00,0 \cdot 05,0 \cdot 10)$ thin films on $\mathrm{Pt}(111) / \mathrm{Ti} / \mathrm{SiO}_{2} / \mathrm{Si}(100)$ substrates and their enhanced ferroelectric and magnetic properties.

\section{Experimental}

Pr and Gd co-modified $\mathrm{Bi}_{0.95-x} \mathrm{Pr}_{x} \mathrm{Gd}_{0.05} \mathrm{FeO}_{3} \quad(x=0.00$, $0 \cdot 05,0 \cdot 10)$ (BPGFO) thin films on $\mathrm{Pt}(111) / \mathrm{Ti} / \mathrm{SiO}_{2} / \mathrm{Si}(100)$ substrates were prepared by a sol-gel together with spin coating technique. Bismuth nitrate $\left[\mathrm{Bi}\left(\mathrm{NO}_{3}\right)_{3} \cdot 5 \mathrm{H}_{2} \mathrm{O}\right]$ (Aldrich, $99.99 \%)$, ferric nitrate $\left[\mathrm{Fe}\left(\mathrm{NO}_{3}\right)_{3} \cdot 9 \mathrm{H}_{2} \mathrm{O}\right]$ were used as the raw materials. $\mathrm{Gd}\left(\mathrm{NO}_{3}\right)_{3} \cdot 6 \mathrm{H}_{2} \mathrm{O}$ and $\operatorname{Pr}\left(\mathrm{NO}_{3}\right)_{3}$ were used as the dopants. 2-methoxyethanol $\left(\mathrm{C}_{3} \mathrm{H}_{8} \mathrm{O}_{2}\right)$ and acetic anhydride $\left[\left(\mathrm{CH}_{3} \mathrm{CO}\right)_{2} \mathrm{O}\right]$ were employed as the solvent and dehydrating agent, respectively. During the preparation of precursor solutions of Pr and Gd co-modified BPGFO thin films, a fixed amount of bismuth nitrate and ferric nitrate were firstly dissolved in 2-methoxyethanol $\left(\mathrm{C}_{3} \mathrm{H}_{8} \mathrm{O}_{2}\right)$ under constant stirring until fully dissolved, and then joined an appropriate $\mathrm{Gd}\left(\mathrm{NO}_{3}\right)_{3} \cdot 6 \mathrm{H}_{2} \mathrm{O}$ and $\operatorname{Pr}\left(\mathrm{NO}_{3}\right)_{3}$ into the completely dissolved solutions with fixed molar ratios of metal ions $\left[n\left(\mathrm{Bi}^{3+}\right): n\left(\mathrm{Pr}^{3+}\right): n\left(\mathrm{Fe}^{3+}\right): n\left(\mathrm{Gd}^{3+}\right)=0.95-x: x: 1: 0 \cdot 05\right.$ $(x=0 \cdot 00,0 \cdot 05,0 \cdot 10)]$. It is worth noting that an excess of $5 \mathrm{wt} \% \mathrm{Bi}$ was added to these solutions to compensate for some unavoidable bismuth oxide loss during the follow-up thermal treatment. Subsequently, a nominal amount of acetic anhydride $\left[\left(\mathrm{CH}_{3} \mathrm{CO}\right)_{2} \mathrm{O}\right]$ was joined into the above-mentioned solutions for dehydrating and appropriate quantity of 2-methoxyethanol was replenished into the formed hybrid solutions to adjust the $\mathrm{Fe}^{3+}$ ions concentration to expected $0.3 \mathrm{~mol} / \mathrm{L}$. Subjected to full stirring and $24 \mathrm{~h}$ aging, the $\mathrm{Pr}$ and Gd co-modified $\mathrm{Bi}_{0.95-x} \mathrm{Pr}_{x} \mathrm{Gd}_{0.05} \mathrm{FeO}_{3}(x=0.00,0.05$, $0 \cdot 10)$ precursor solutions were successfully made.

Prior to preparing the BPGFO thin films, the $\mathrm{Pt}(111)$ / $\mathrm{Ti} / \mathrm{SiO}_{2} / \mathrm{Si}(100)$ substrates were cleaned by ultra-sonication in acetone and alcohol and dried with nitrogen gas. And then, the BPGFO precursor solutions were spin-coated on the cleaned $\mathrm{Pt}(111) / \mathrm{Ti} / \mathrm{SiO}_{2} / \mathrm{Si}(100)$ substrates at a rate of $3300 \mathrm{rpm}$ for $15 \mathrm{~s}$. The wet films were preheated over a hotplate at $350^{\circ} \mathrm{C}$ for $5 \mathrm{~min}$, followed by a pyrolysis process at $500{ }^{\circ} \mathrm{C}$ for $5 \mathrm{~min}$. The coating and thermal treatment process was repeated twelve times and then these films were annealed at $600^{\circ} \mathrm{C}$ for $20 \mathrm{~min}$ in air by a rapid thermal annealing process for full crystallization. Finally, the thickness of resultant films was around $230 \mathrm{~nm}$.

The crystal structures of Pr and Gd co-modified BPGFO thin films were investigated by the $\theta-2 \theta$ method of XRD with a $\mathrm{CuK} \alpha_{1}(\lambda=0.15406 \mathrm{~nm})$ source at $40 \mathrm{kV}$ and $30 \mathrm{~mA}$ using a multi-purpose XRD system (D/MAX-RB). For electrical measurements, a gold thin film was coated on the surface of these samples with an area of $5.25 \times 10^{-5} \mathrm{~cm}^{-2}$ using a shadow mask and then sintered at $550^{\circ} \mathrm{C}$ for $15 \mathrm{~min}$ in an $\mathrm{N}_{2}$ atmosphere. The ferroelectric hysteresis loops together with leakage current behaviours of these thin films were obtained using a ferroelectric tester (Radiant Technologies, RT66A). The dielectric constant and the dissipation factor were measured using an HP4294A impedance analyzer. A vibrating sample magnetometer (VSM) was employed to measure the magnetic properties. All the measurements were performed at room temperature.

\section{Results and discussion}

Figure 1 shows the XRD patterns of Pr and Gd co-modified $\mathrm{Bi}_{0.95-x} \mathrm{Pr}_{x} \mathrm{Gd}_{0.05} \mathrm{FeO}_{3}(x=0 \cdot 00,0 \cdot 05,0 \cdot 10)$ (BPGFO) thin films grown on $\mathrm{Pt}(111) / \mathrm{Ti} / \mathrm{SiO}_{2} / \mathrm{Si}(100)$ substrates. All the diffraction peaks are identified and indexed according to the standard diffraction pattern data (Sosnowska et al 1996). The XRD patterns indicate that these BPGFO thin films are polycrystalline with a perovskite structure belonging to the space group of R3c. The diffraction peaks from welldocumented impurity phases such as $\mathrm{Bi}_{2} \mathrm{Fe}_{4} \mathrm{O}_{9}$ (Fe-rich phase) and $\mathrm{Bi}_{36} \mathrm{Fe}_{24} \mathrm{O}_{57}$ (Bi-rich phase) were not detected. When magnifying the (110) diffraction peaks around $2 \theta=$ $32^{\circ}$ (figure 1), it was observed that the (110) peak shifted towards high diffraction angles gradually with increasing $\operatorname{Pr}$ concentration. This phenomenon indicates that Pr doping leads to some kind of structural distortion. The diffraction peak shifting towards high diffraction angles is due to the decrease of BPGFO lattice spacing. Both the ionic radius of $\mathrm{Gd}^{3+}(1.11 \AA)$ and that of $\mathrm{Pr}^{3+}(1.126 \AA)$ are smaller than that of $\mathrm{Bi}^{3+}(1 \cdot 17 \AA)$ (Yu et al 2008). And thus, the decrease of BPGFO lattice spacing may be attributed to the incorporation of $\mathrm{Pr}$ and $\mathrm{Gd}$ ions into the A-site of $\mathrm{BFO}$

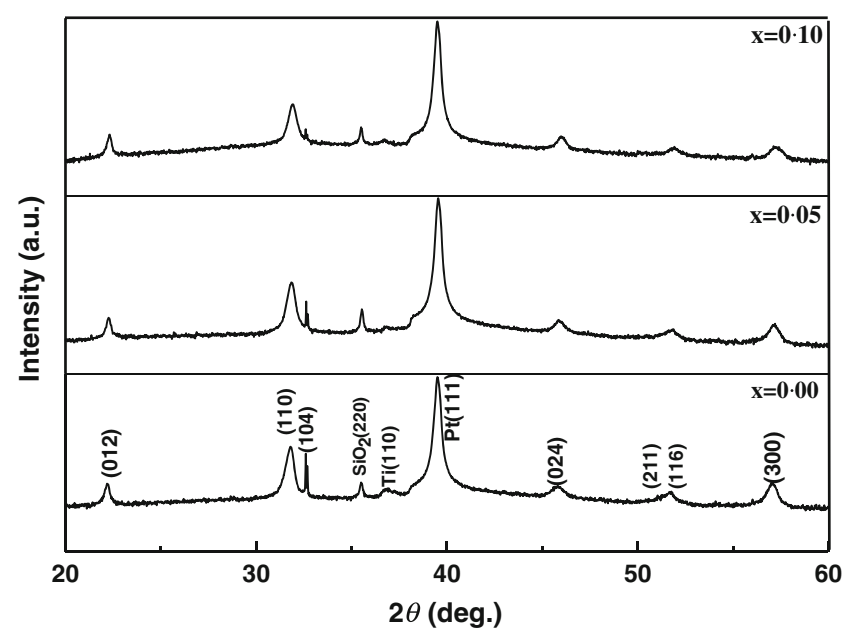

Figure 1. X-ray diffraction patterns of the $\mathrm{Bi}_{0 \cdot 95-x} \mathrm{Pr}_{x} \mathrm{Gd}_{0.05}$ $\mathrm{FeO}_{3}(x=0 \cdot 00,0 \cdot 05,0 \cdot 10)$ thin films grown on $\mathrm{Pt}(111) / \mathrm{Ti} / \mathrm{SiO}_{2} /$ $\mathrm{Si}(100)$ substrates. 
materials. In addition, with an increase of Pr doping concentration in $\mathrm{Bi}_{0.95-x} \mathrm{Pr}_{x} \mathrm{Gd}_{0.05} \mathrm{FeO}_{3}$, the intensity of (104) diffraction peaks were found to gradually decrease.

Figure 2 shows the ferroelectric behaviour of Pr and Gd co-modified BPGFO thin films as a function of electric field. For the $\mathrm{Gd}$ co-modified $\mathrm{Bi}_{0.95} \mathrm{Gd}_{0.05} \mathrm{FeO}_{3}(x=0 \cdot 00)$ thin films, a ferroelectric hysteresis loop is observed with saturation polarization of $5.8 \mu \mathrm{C} / \mathrm{cm}^{2}$. With an increased concentration of $\mathrm{Pr}$ in $\mathrm{Pr}$ and $\mathrm{Gd}$ co-modified $\mathrm{Bi}_{0.95-x} \mathrm{Pr}_{x} \mathrm{Gd}_{0.05} \mathrm{FeO}_{3}(x=0.05)$, the saturation polarization value increases to $6.03 \mu \mathrm{C} / \mathrm{cm}^{2}$. When the substitution of a Bi site by $\mathrm{Pr}$ ion with a concentration of $0 \cdot 10$, the saturation polarization value in the $\mathrm{Pr}$ and $\mathrm{Gd}$ co-modified $\mathrm{Bi}_{0.95-x} \mathrm{Pr}_{x} \mathrm{Gd}_{0.05} \mathrm{FeO}_{3}$ thin film increases to $7.36 \mu \mathrm{C} / \mathrm{cm}^{2}$. Consequently, the incorporation of Pr ions into the Bi site of the BFO thin film is noticeably attributed to the improvement of ferroelectric performance of pure BFO thin films. Compared to the saturation polarization value of $\mathrm{Bi}_{0.95} \mathrm{Gd}_{0.05} \mathrm{FeO}_{3}$ thin film, the enhanced saturation polarization values in $\mathrm{Bi}_{0.90} \mathrm{Pr}_{0.05} \mathrm{Gd}_{0.05} \mathrm{FeO}_{3}, \mathrm{Bi}_{0.85} \mathrm{Pr}_{0.1} \mathrm{Gd}_{0.05} \mathrm{FeO}_{3}$ thin films are probably ascribed to their low leakage current density (figure 4).

Figure 3 shows the variation of dielectric constant $\left(\varepsilon_{\mathrm{r}}\right)$ and dissipation factor $(\tan \delta)$ as a function of applied frequency for the Pr and Gd co-modified BPGFO thin films measured at room temperature. In the low frequency range, both $\varepsilon_{\mathrm{r}}$ and $\tan \delta$ have very high values. With an increase of applied frequency, $\varepsilon_{\mathrm{r}}$ together with $\tan \delta$ for all the thin films gradually decrease and then they are nearly constant at high frequencies. This decrease in the dielectric constant in the frequency range is likely caused by space charge polarization or Maxwell Wagner type interfacial polarization (Okatan et al 2010). The decrease in $\tan \delta$ correlates with the corresponding changes in the electrical resistivity. At a fixed frequency, $\varepsilon_{\mathrm{r}}$ of $\mathrm{Bi}_{0.85} \operatorname{Pr}_{0.1} \mathrm{Gd}_{0.05} \mathrm{FeO}_{3}$

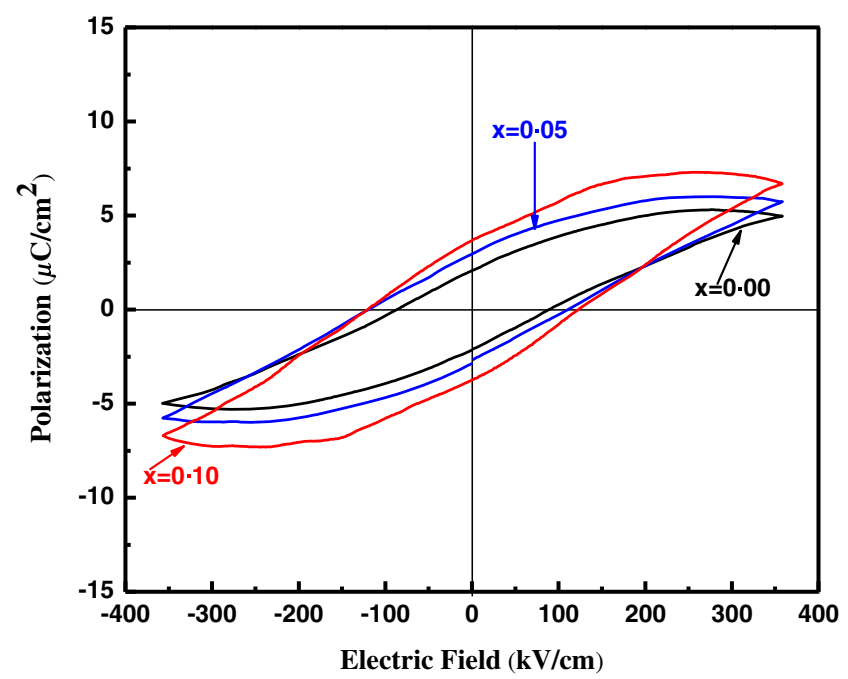

Figure 2. Electric hysteresis loops of $\mathrm{Bi}_{0.95-x} \mathrm{Pr}_{x} \mathrm{Gd}_{0.05} \mathrm{FeO}_{3}$ $(x=0.00,0.05,0 \cdot 10)$ thin films grown on $\mathrm{Pt}(111) / \mathrm{Ti} / \mathrm{SiO}_{2} /$ $\mathrm{Si}(100)$ substrates. thin films is the largest, which is beneficial to its optimal saturation polarization values (online $2 \mathrm{Pr}$ ), shown in figure 2. On the other hand, at a fixed frequency, $\tan \delta$ of the $\mathrm{Bi}_{0.85} \operatorname{Pr}_{0.1} \mathrm{Gd}_{0.05} \mathrm{FeO}_{3}$ thin films is also the least. Consequently, the largest dielectric constant value of the $\mathrm{Bi}_{0.85} \operatorname{Pr}_{0.1} \mathrm{Gd}_{0.05} \mathrm{FeO}_{3}$ thin films coincides with its least dissipation factor. Higher dissipation factors generally represent large leakage current due to higher conductivity. A decrease in the value of dissipation factor for Pr and Gd co-modified BPGFO thin films suggests that Pr substitution is helpful in reducing the leakage current. Consequently, the ferroelectric material with the largest dielectric constant together with the least dissipation factors is advantageous for any device application.

Figure 4 shows the $I-V$ characteristics of $\mathrm{Au} / \mathrm{Pr}$ and Gd co-modified BPGFO thin films/Pt capacitors annealed at $550^{\circ} \mathrm{C}$ for $15 \mathrm{~min}$ in an $\mathrm{N}_{2}$ atmosphere and measured at room temperature. The leakage current density of all the capacitors increases rapidly with an increase in the initially applied electric field. The leakage current densities of $\mathrm{Au} / \mathrm{Bi}_{0.95} \mathrm{Gd}_{0.05} \mathrm{FeO}_{3} / \mathrm{Pt}, \mathrm{Au} / \mathrm{Bi}_{0.9} \mathrm{Pr}_{0.05} \mathrm{Gd}_{0.05} \mathrm{FeO}_{3} / \mathrm{Pt}$, $\mathrm{Au} / \mathrm{Bi}_{0.85} \mathrm{Pr}_{0.10} \mathrm{Gd}_{0.05} \mathrm{FeO}_{3} / \mathrm{Pt}$, capacitor at the maximum applied field $350 \mathrm{kV} / \mathrm{cm}$ are about $9.38 \times 10^{-5}, 1.75 \times$ $10^{-6}, 5.97 \times 10^{-7} \mathrm{~A} / \mathrm{cm}^{2}$, respectively. It is well known that a mixed-valence state of $\mathrm{Fe}^{2+/ 3+}$ exists in the pure $\mathrm{BFO}$ materials due to the presence of oxygen and $\mathrm{Bi}$ vacancies. Electron transfer probably takes place between these ions and thus pure BFO presents higher conductivity. $\mathrm{Gd}^{3+}$ ions and $\mathrm{Pr}^{3+}$ co-substitution at Bi-site lead to the suppression in Bi-volatilization and the oxygen vacancies. As a result, the Pr and Gd co-modified BPGFO thin film exhibits a lower leakage current density. The lower leakage current density brings about lower dielectric loss values in Pr and Gd co-modified BPGFO thin films as shown in figure 3. The lower dielectric loss at a low frequency of

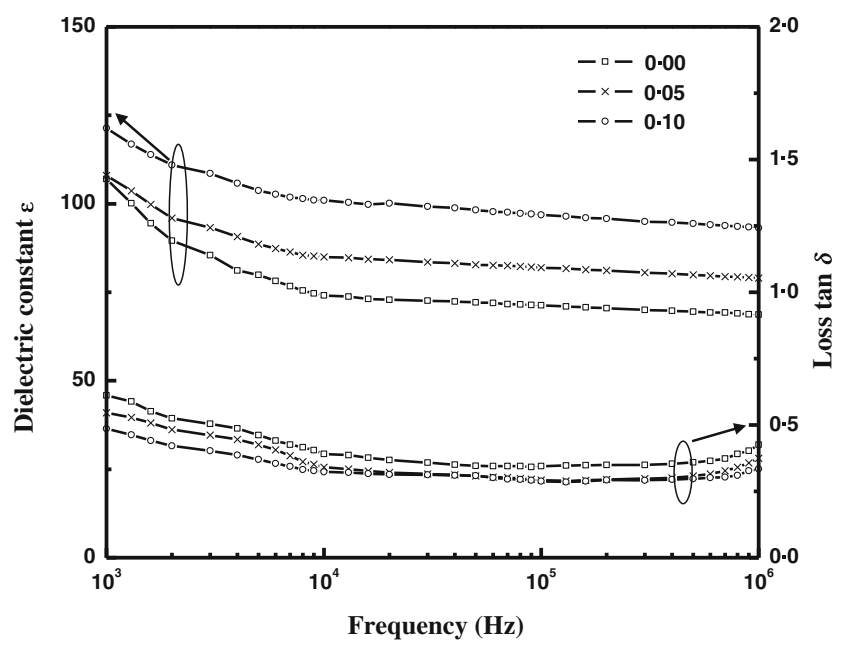

Figure 3. Dielectric constant $\left(\varepsilon_{\mathrm{r}}\right)$ and dissipation factor $(\tan \delta)$ in dependence of frequency for the $\mathrm{Bi}_{0.95-x} \mathrm{Pr}_{x} \mathrm{Gd}_{0.05} \mathrm{FeO}_{3}$ $(x=0 \cdot 00,0 \cdot 05,0 \cdot 10)$ thin films grown on $\mathrm{Pt}(111) / \mathrm{Ti} / \mathrm{SiO}_{2} / \mathrm{Si}(100)$ substrates. 


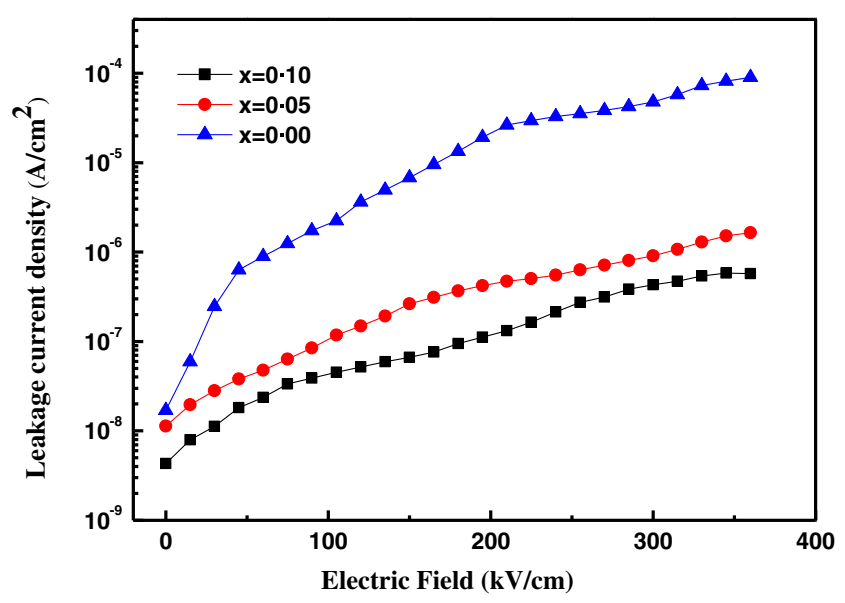

Figure 4. $I-V$ characteristics of the $\mathrm{Bi}_{0.95-x} \operatorname{Pr}_{x} \mathrm{Gd}_{0.05} \mathrm{FeO}_{3}$ $(x=0.00,0.05,0 \cdot 10)$ thin films grown on $\mathrm{Pt}(111) / \mathrm{Ti} / \mathrm{SiO}_{2} /$ $\mathrm{Si}(100)$ substrates.

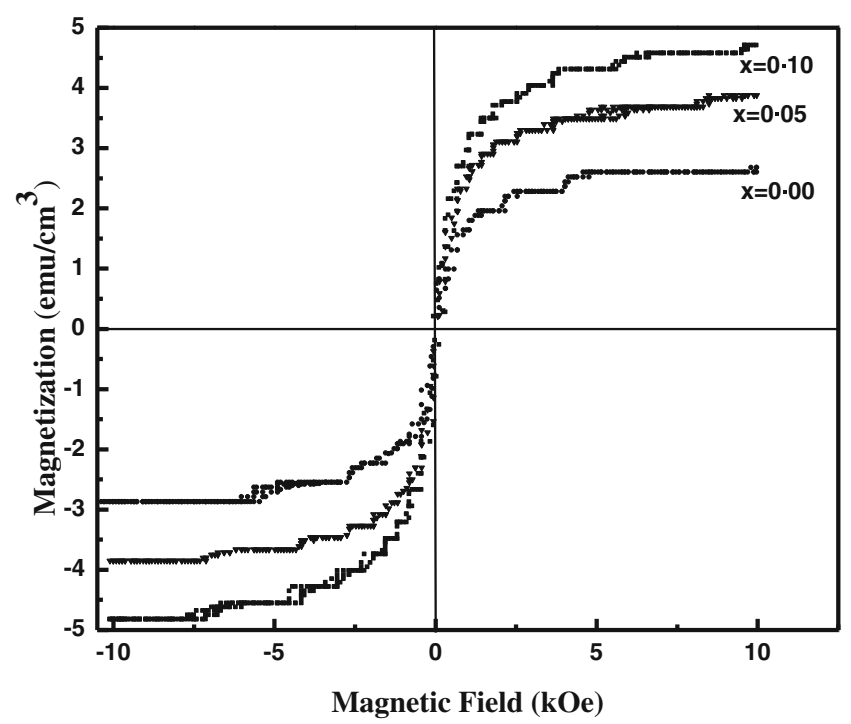

Figure 5. Magnetization variation with applied magnetic field of the $\mathrm{Bi}_{0.95-x} \mathrm{Pr}_{x} \mathrm{Gd}_{0.05} \mathrm{FeO}_{3}(x=0,0.05,0 \cdot 10)$ thin films on $\mathrm{Pt}(111) / \mathrm{Ti} / \mathrm{SiO}_{2} / \mathrm{Si}(100)$ substrates at room temperature.

$\mathrm{BiFeO}_{3}$ thin films at room temperature reflects their lower leakage currents (Yun et al 2004).

Room temperature magnetization-magnetic field $(M-H)$ curves of Pr and Gd co-modified BPGFO thin films measured with magnetic field of $10 \mathrm{kOe}$ are shown in figure 5 . Owing to the remanant magnetization $\left(M_{\mathrm{r}}\right)$ and coercive field $\left(H_{\mathrm{c}}\right)$ nearly being equal to zero, all the BPGFO thin film samples show weak hysteresis loops representing paramagnetic behaviour. With an increase of Pr doping content in $\mathrm{Bi}_{0.95-x} \mathrm{Pr}_{\mathrm{x}} \mathrm{Gd}_{0.05} \mathrm{FeO}_{3}$ thin film, an enhanced saturation magnetization is observed in figure 5. It is well-established that the spin cycloid of BFO, with latent magnetization locked within the cycloid, is related to its R3c structure, substituents can perturbate its spiral spin structure and, if it is destructed, the magnetization tends to increase (Wang et al
2005). In our study, because of the incorporation of Pr and Gd ions into the A-site of BFO materials and with an increase of Pr doping concentration in $\mathrm{Bi}_{0.95-x} \mathrm{Pr}_{x} \mathrm{Gd}_{0.05} \mathrm{FeO}_{3}$ $(x=0.00,0.05,0.10)$ thin films, the structural distortion originated from decreases in lattice spacing. Consequently, it is reasonable that the improved magnetic properties BPGFO thin films could be obtained in figure 5. For the merit of codoping in BFO thin film, the enhanced saturation magnetization values are also found in the other Co-Pr substituted thin films (Neeraj Panwar et al 2012).

\section{Conclusions}

In summary, the $\mathrm{Pr}$ and $\mathrm{Gd}$ co-modified $\mathrm{Bi}_{0.95-x} \mathrm{Pr}_{x} \mathrm{Gd}_{0.05}$ $\mathrm{FeO}_{3}(x=0.00,0.05,0 \cdot 10)$ thin films grown on $\mathrm{Pt}(111) /$ $\mathrm{Ti} / \mathrm{SiO}_{2} / \mathrm{Si}(100)$ substrates were synthesized by a sol-gel together with a spin-coating method and their structures and properties were studied. When varying the substitution of a $\mathrm{Bi}$ site by $\mathrm{Pr}$ ions in $\mathrm{Bi}_{0.95-x} \mathrm{Pr}_{x} \mathrm{Gd}_{0.05} \mathrm{FeO}_{3}$ $(x=0 \cdot 00,0 \cdot 05,0 \cdot 10)$ thin films, the structural distortion and an enhanced ferroelectric polarization at room temperature could be found. In addition, with an increase in Pr content, the dielectric constant increases, whereas both leakage current density and the dielectric loss decrease. The enhanced saturation magnetic properties are also observed for the $\mathrm{Pr}$ and $\mathrm{Gd}$ co-modified $\mathrm{Bi}_{0.95-x} \mathrm{Pr}_{x} \mathrm{Gd}_{0.05} \mathrm{FeO}_{3}(x=0.00,0.05$, $0 \cdot 10)$ thin films with an increase in Pr content.

\section{Acknowledgements}

This study is partially financed by the Priority Academic Program Development of Jiangsu Higher Education Institutions (PAPD), China, and also partially supported by University Students' innovative undertaking training program of higher education of Jiangsu Province (granted number: 201410291004Z).

\section{References}

Dean J A 1999 Lange's handbook of chemistry 15th edn (New York: McGraw-Hill)

Eerenstein W, Mathur N D and Scott J F 2006 Nature 442759

Fiebig M, Lottermoser Th, Fröhlich D, Goltsev A V and Pisarev R V 2002 Nature 419818

Hill N A 2000 J. Phys. Chem. B104 6694

Hur N, Park S, Sharma P A, Ahn J S, Guha S and Cheong S W 2004 Nature 429392

Kumar M and Yadav K L 2006 J. Appl. Phys. 100074111

Lee Y-H, Wu J-M and Lai C-H 2006 Appl. Phys. Lett. 88042903

Munoz T, Rivera J P, Monnier A and Schmid H 1985 Jpn. J. Appl. Phys. Part 1241051

Naik V B and Mahendiran R 2009 Solid State Commun. 149754

Neeraj Panwar, Indrani Coondoo, Amit Tomar, Kholkin A L, Venkata S Puli and Ram S Katiyar 2012 Mater. Res. Bull. 474240 Okatan M B, Mantese J V and Alpay S P 2010 Acta Materialia 5839 Palkar Y R, Kundaliya D C, Malik S K and Bhattacharya S 2004 Phys. Rev. B69 212102 
Qi X D, Dho J, Tomov R, Blamire M G and MacManus-Driscoll J L 2005 Appl. Phys. Lett. 86062903

Singh V, Sharma S, Kumar M, Dwivedi R K and Kotnala R K 2013 Phys. Status Solidi. A210 1442

Smolenskii G A and Chupis L 1982 Soviet Physics Uspekhi 25475

Sosnowska I, Przenioslo R, Fischer P and Murashov V A 1996 J. Magn. Magn. Mater. 160384

Takeshi Kawae, Hisashi Tsuda, Hiroshi Naganuma, Satoru Yamada, Minoru Kumeda, Soichiro Okamura and Akiharu Morimoto 2008 Jpn. J. Appl. Phys. 477586
Wang N, Cheng J, Pyatakov A, Zvezdin A K, Li J F, Cross L E and Viehland D 2005 Phys. Rev. B72 1044341

Yu B, Li M, Hu Z, Pei L, Guo D, Zhao X and Dong S 2008 Appl. Phys. Lett. 93182909

Yuan G L, Or S W, Wang Y P, Liu Z G and Liu J M 2006 Solid State Commun. 13876

Yun K Y, Noda M, Okuyama M, Saeki H, Tabata H and Saito K 2004 J. Appl. Phys. 963399

Zhang S-T, Zhang Y, Liu M, Du C, Chen Y, Liu Z, Zhu Y and Ming N-B 2006 Appl. Phys. Lett. 88162901 